\title{
Epistemic Exploitation
}

\author{
NORA BERENSTAIN \\ University of Tennessee, Knoxville
}

\begin{abstract}
Epistemic exploitation occurs when privileged persons compel marginalized persons to educate them about the nature of their oppression. I argue that epistemic exploitation is marked by unrecognized, uncompensated, emotionally taxing, coerced epistemic labor. The coercive and exploitative aspects of the phenomenon are exemplified by the unpaid nature of the educational labor and its associated opportunity costs, the double bind that marginalized persons must navigate when faced with the demand to educate, and the need for additional labor created by the default skepticism of the privileged. I explore the connections between epistemic exploitation and the two varieties of epistemic injustice that Fricker (2007) identifies, testimonial and hermeneutical injustice. I situate epistemic exploitation within Dotson's (2012; 2014) framework of epistemic oppression, and I address the role that epistemic exploitation plays in maintaining active ignorance and upholding dominant epistemic frameworks.
\end{abstract}

\section{Introduction}

Black and Third-World people are expected to educate white people as to our humanity. Women are expected to educate men. Lesbian and gay men are expected to educate the heterosexual world. The oppressors maintain their position and evade their responsibility for their own actions. There is a constant drain of energy which might be better used in redefining ourselves and devising realistic scenarios for altering the present and constructing the future. (Audre Lorde 1995)

It is physically and emotionally draining to be called upon to prove that these systems of power exist. For many of us, just struggling against them is enough - now you want us to break them down for you? (Julianna Britto Schwartz 2014)

Contact: Nora Berenstain <nberenst@utk.edu> 
The function, the very serious function, of racism is distraction. It keeps you from doing your work. It keeps you explaining, over and over again, your reason for being. Somebody says you have no language, so you spend twenty years proving that you do. Somebody says your head isn't shaped properly, so you have scientists working on the fact that it is. Somebody says you have no art, so you dredge that up. Somebody says you have no kingdoms and so you dredge that up. None of that is necessary. There will always be one more thing. (Toni Morrison 1975)

\section{What Is Epistemic Exploitation?}

The phenomenon that Lorde, Britto Schwartz, Morrison, and many others have identified and criticized is what I term epistemic exploitation. Epistemic exploitation occurs when privileged persons compel marginalized persons to produce an education or explanation about the nature of the oppression they face. ${ }^{1}$ Epistemic exploitation is a variety of epistemic oppression marked by unrecognized, uncompensated, emotionally taxing, coerced epistemic labor. It maintains structures of oppression by centering the needs and desires of dominant groups and exploiting the emotional and cognitive labor of members of marginalized groups who are required to do the unpaid and often unacknowledged work of providing information, resources, and evidence of oppression to privileged persons who demand it-and who benefit from those very oppressive systems about which they demand to be educated.

Epistemic exploitation is ubiquitous. It is common within institutions of higher education, activist coalitions and alliances, and interpersonal relationships. Despite its pervasiveness, however, it is not widely recognized as a component of epistemic or social and political oppression. Rather, it masquerades as a necessary and even epistemically virtuous form of intellectual engagement, and it is often treated as an indispensable method of attaining knowledge. Epistemic exploitation goes by many other names. Standard conversational norms

1. This account assumes an intersectional picture of privilege and oppression. Epistemic exploitation occurs across dimensions of hegemonic difference. Someone is a marginalized person within a context of epistemic exploitation if they experience the oppression about which the education is demanded and the person demanding it does not. A man's demand that a woman explain the nature of sexism is epistemically exploitative since the woman experiences sexism and the man does not. In that context the woman is a marginalized person, though this would not be true for every context. A cisgender woman demanding an explanation of cissexism from a trans or gender non-conforming person is engaging in epistemic exploitation. In that context where cissexism and cissupremacy are the oppressions in question, a cisgender woman would not count as a marginalized person. 
allow epistemic exploitation to masquerade as any number of acceptable and normalized practices-'exercising harmless curiosity,' 'just asking a question,' 'making a well-intentioned effort to learn,' 'offering alternative explanations,' and 'playing devil's advocate' are a few of the labels used to describe epistemically exploitative interactions. These innocuous euphemisms all help to mask the oppressive power dynamics at play in instances of epistemic exploitation.

That many of these euphemistic covers frame epistemic exploitation as a virtuous epistemic practice related to the pursuit of truth is one reason that the practice is both widespread and vigorously defended. This creates a burden on the marginalized to educate and enlighten. Though the privileged demand the epistemic labor of the marginalized, they often perpetuate epistemic oppression by dismissing the knowledge produced. The marginalized are excluded from the realm of recognized knowledge creators despite contributing novel conceptual resources and epistemic frameworks. The rhetorical obfuscations surrounding epistemic exploitation make the naming and explication of the phenomenon critical to developing strategies of resistance to epistemic oppression.

As the insights of Lorde, Britto Schwartz, and Morrison indicate, the practice of epistemic exploitation has long been acknowledged and critiqued by women of color activists and scholars. But despite the level of attention and discussion that it has received in these intellectual spaces, epistemic exploitation remains under-theorized within academic philosophy. While the expansive literature on epistemic injustice details a number of ways in which structural power determines the distribution, attribution, and social dimensions of knowledge, it has yet to explicitly analyze this particular phenomenon. The task of this paper is to elucidate the phenomenon of epistemic exploitation and situate it in the framework of epistemic oppression. This investigation will identify the harms of epistemic exploitation, illuminate the structural disparities that allow it to take place, and reveal the role it plays in reproducing active ignorance and maintaining systems of oppression.

\section{What Is Exploitative about Epistemic Exploitation?}

Epistemic exploitation can take many forms. It can be perpetrated through wellintentioned requests to help one learn about oppression. It can also take the form of default skepticism toward individual experiences of bias, microaggressions, or harassment. Such responses demand that the victim do the emotionally exhausting work of reliving their experience and defending their interpretation of it in the face of doubt and disbelief. Default skeptical responses also function to erase existing epistemic resources that undermine dominant narratives about the relationship of these experiences to larger structures of oppression. Even 
generally treating the existence of oppressive systems as up for debate can require those who are oppressed by these systems to do the emotionally exhausting labor of justifying and substantiating their experiences.

The exploitative nature of epistemic exploitation derives from several of its features. These include the opportunity costs associated with the labor of educating the oppressor, the double bind that marginalized people find themselves in when faced with the demand to educate, and the default skeptical responses from the privileged when the marginalized do acquiesce and fulfill their demands.

\subsection{Unpaid Labor and Opportunity Costs}

A central feature of epistemic exploitation is that the labor demanded is unpaid and frequently unacknowledged.

In an article responding to actress Patricia Arquette's privileged antiintersectional backstage comments ${ }^{2}$ after her best-actress acceptance speech at the 2015 Academy Awards, Rutgers Professor and Salon columnist Brittney Cooper explicitly refuses to do the work that white feminists expect her to do and that has been done repeatedly by many Black feminists before her. She notes the irony of a white feminist calling for wage equality while also implicitly demanding that Black women do the unpaid work of educating her about the pay gap's racial dimensions:

If among feminists, black women are always asked to do the uncompensated labor of educating white women about how they have effed up, is this also not a form of wage inequality? Are these not also the wages

2. Arquette's backstage comments were,

It's time for women. Equal means equal. The truth is the older women get, the less money they make. The highest percentage of children living in poverty are in female-headed households ... So the truth is even though we sort of feel like we have equal rights in America right under the surface there are huge issues at play that really do affect women. It's time for all the women in America, and all the men that love women and all the gay people and all the people of color that we've all fought for to fight for us now. (Ajayi 2015)

Her comments ignore the fact that women, queer people, and people of color are overlapping groups that face intersecting oppressions. Further, Arquette suggests that people of color have an obligation to support the campaign of wealthy and middle-class white women who want to receive pay equal to what white men receive. She implies that this is because people of color are indebted to white women for the solidarity that white women have shown in struggles for civil rights and racial justice. She ignores and obscures the fact that white women continue to participate in and benefit from white supremacy and the capitalist exploitation of people of color, and she adds insult to injury by suggesting that people of color owe their labor to the promotion of class-privileged white women's interests. 
of race at play? Some of my academic colleagues of color call this "the black or people of color tax" - the extra, and often unacknowledged labor, time and resources we give to institutions, that our white colleagues don't have to do and for which we are uncompensated, in order to help struggling students of color navigate our institutions and insure diversity at the levels of faculty and administration.

If I ramp up my cortisol levels to express my anger and hurt at white women for failing once again to get it, is that not a tax and toll on my health that I pay either in future medical bills or in years unlived? (Cooper 2015)

Cooper emphasizes a number of features of epistemic exploitation through her characterization of the burdens that white women expect Black women and other women of color to bear. It is simply assumed that they will provide the necessary labor to correct white women's mistakes, even though this labor is financially uncompensated, time-consuming, mentally draining, and rarely even recognized as work.

Epistemic exploitation levies a tax in "years unlived" because the labor it requires is often the source of significant negative emotion that itself takes labor to dispel. ${ }^{3}$ Marginalized persons frequently have symptoms of psychological distress and trauma resulting from their experiences of oppression (Pieterse, Todd, Neville, \& Carter 2012; Clark, Clark, \& Williams 1999; Landrine, Klonoff, Gibbs, Manning, \& Lund 1995). In order for marginalized persons to do the labor of educating others about their oppression, they must first overcome the cognitive burden of dispelling the negative emotion associated with it. This makes performing educational labor about oppression significantly more costly for someone who experiences it than for someone who does not. As Cooper emphasizes, when marginalized persons are called on to educate their oppressors, they bear increased cognitive and emotional costs that take a cumulative toll on their mental and physical health.

Cooper's comments also point to a way in which epistemic exploitation is built into the structure of academia. Because many predominantly white institutions of higher education have only a lip-service commitment to diversity, members of marginalized groups are often called upon to serve on committees and attend meetings in order for their under-represented group to appear to be better represented, though often not beyond the token level. ${ }^{4}$ Faculty of color, particu-

3. Thanks to Kristie Dotson for making this point in her comments on this paper at the 2016 Central APA.

4. Because the neoliberal university profits from increasing diversity but lacks a corresponding commitment to changing the institutionalized white supremacy that creates the need for diversity-promoting efforts in the first place, most diversity initiatives simply maintain the status 
larly women of color, bear a disproportionate burden compared to white faculty when it comes to expectations of mentorship and advising (Cox 2008), serving on committees (Wilson 2015), sponsoring student organizations, and providing informal guidance and counseling to students of colors faced with navigating the racism that pervades predominantly white institutions (Niemann 1999). Canton notes that while the additional service that the university demands of faculty of color "may bring accolades to the institution, it is not usually rewarded by the institution on whose behalf the service was performed" (2013: 10). Institutions of higher education often demand that faculty of color provide knowledge or education for diversity training and other programs that specifically depend on marginalized people sharing information about their experiences, perspectives, and marginalization within the academy. When this labor goes uncompensated and unrecognized, as it so often does, these institutional demands on faculty of color result in epistemic exploitation.

That exploitative diversity work rarely leads to actual institutional change illustrates another injurious feature of epistemic exploitation. More often than not, the labor demanded is provided in vain. Cooper writes,

Asking black women and other women of color always to explain, show and prove to white people what is so wrong about what they have said or done, when we have no guarantees that they will change, shift or grow, is unacceptable. I demand better conditions of work. (2015)

In addition to being cognitively costly, unrecognized, and unpaid, the work that marginalized people provide through epistemic exploitation is frequently dismissed by those who demand it. Nothing comes of it. Oppressors demand labor and then leave the fruits of the labor to spoil and perish. This reveals an important function of epistemic exploitation: to keep the oppressed busy doing the oppressor's work.

Women of today are still being called upon to stretch across the gap of male ignorance and to educate men as to our existence and our needs. This is an old and primary tool of all oppressors to keep the oppressed occupied with the master's concerns. Now we hear that it is the task of

quo. Ahmed notes that, "diversity can be a method of protecting whiteness" and it is often "mobilized as a defense of reputation" (2012: 147, 151). Kळra theorizes that diversity is the practice of mixing together different bodies within a common organization, and is a prime resource to be capitalized upon by businesses and organizations that are white-owned and/or operated. Diversity still benefits those in power by taking advantage of the various experiences and vantage points of different racial/gender/sexual backgrounds. Rather than respecting difference and redistributing power based on it, diversity only 'celebrates' difference in order to exploit multiculturalism for its economic value. (2014) 
women of Color to educate white women - in the face of tremendous resistance-as to our existence, our differences, our relative roles in our joint survival.

This is a diversion of energies and a tragic repetition of racist patriarchal thought. (Lorde 2007)

Because it always involves a "diversion of energies," epistemic exploitation comes with opportunity costs. The obligation to educate their oppressors consumes the attention of the oppressed, preventing it from being put to better use. 5 This opportunity cost makes the demand for educational labor epistemically exploitative even absent the "tremendous resistance" that generally accompanies it. It may be tempting to say that an exchange is not epistemically exploitative if upon being educated the privileged start pushing back in tangible ways against the oppressive systems that afford them their privilege and become allies or active bystander at some cost to themselves. ${ }^{6}$ But even if the educational labor that the marginalized provide inspires the privileged to further study oppressive systems and begin working to undermine them, the marginalized have still sacrificed their time, energy, and expertise in the service of the privileged. The privileged receive social recognition from their newfound knowledge and selfimprovement that are rarely conferred on the marginalized persons who produce this knowledge. Epistemic exploitation thus bestows benefits on the privileged while the marginalized bear the costs.

\subsection{The Double Bind}

Let me tell you what it feels like to stand in front of a white man and explain privilege to him. It hurts. It makes you tired. Sometimes it makes you want to cry. Sometimes it is exhilarating. Every single time it is hard. Every single time I get angry that I have to do this, that this is my job, that this shouldn't be my job. Every single time I am proud of myself that I've been able to say these things because I used to not be able to and because some days I just don't want to. (Manissa McCleave Maharawal 2011)

Maharawal points to an important feature of epistemic exploitation, which is that the labor demanded is always expected of her. It is her job to engage and

5. Hannah Giorgis warns against devoting one's efforts to a project that was never intended to succeed. She writes, "Do not waste time \& energy explaining your humanity to people committed to denying it. Invest in your community instead" (2014).

6. See McKenzie (2014) and Giorgis (2012) for explicit ways that allies and active bystanders are called upon to undermine the systems of oppression responsible for their privilege. 
educate whether she wants to or not. Because the privileged feel entitled to the time and energy of the marginalized, if Maharawal fails to provide the labor expected of her, she will be seen as shirking a duty and will thus open herself up to reprobation. Marginalized persons often do not have the option to simply disengage from an epistemically exploitative situation without being subjected to harm as a result of their perceived affront. This is the double bind.

The existence of the double bind means that there is little possibility of a marginalized person choosing to engage an epistemically exploitative demand without fear of what might happen if they refuse. ${ }^{7}$ Consider the following situation in which a marginalized person faces a double bind when confronted with an epistemically exploitative demand. Suppose Amina, a Black woman, is out with a white male acquaintance, Ben, when a white woman approaches her, reaches out to touch her hair, and exclaims how soft it is. Amina tells the white woman not to touch her hair. The white woman, offended, says "I was just trying to give you a compliment," and leaves angrily. Ben then asks why Amina was "so rude" to the woman who was "just being nice." Amina is tired and does not feel like defending her right to bodily autonomy or explaining the history of white objectification of Black women's bodies and the racist entitlement that is inherent in a white person touching a Black woman without her permission. However, Amina knows that if she refuses to explain herself to Ben or simply says, "I don't want to talk about it," she runs the risk of being painted as overly emotional, irrational, hypersensitive, unfriendly, and aggressive. Amina thus faces a double bind: She can either engage in the coerced labor of explaining why the white woman's action was racist and justifying her response to it, or she can risk being seen as confirming the misogynoiristic ${ }^{8}$ controlling image of the Angry Black Woman. ${ }^{9}$

7. This is not to say that a marginalized person cannot genuinely choose to engage with a privileged person on topics of the oppression they face. They may even choose to make themselves generally available as an educational resource about their oppression to those who want to learn about it and do not experience it. But it must be their choice rather than something that they are coerced into out of concern for their safety and well-being.

8. Moya Bailey created the term "misogynoir" to describe the racialized misogyny and gendered anti-Black racism that Black women uniquely face. The word first appeared in Bailey's (2010) essay "They aren't talking about me ..." on Crunk Feminist Collective. See Bailey (2014) for the origin story of the term and Trudy (2014) for further explication of the concept.

9. Jacobsen (2015) recounts numerous instances of white people touching and commenting on her hair in objectifying ways. She also discusses the challenge of navigating these racist interactions while trying to avoid being perceived as confirming the controlling image of the Angry Black Woman. Meyerson (2015) describes an experience at the Metropolitan Opera in which a white man asked her to put her hair up because it was blocking his wife's view. After initially complying with the request, Meyerson turned around at intermission to let the man know that she would be taking her hair back down for the remainder of the show. He responded, "You're really disgusting. Who comes to the opera with their hair sticking straight out of their head like that?" His verbally abusive outburst evokes racist stereotypes of Black people as uncivilized and animalistic and express- 
While marginalized people often face blowback if they disengage from situations involving epistemically exploitative demands, neither can they protect themselves from hostility by choosing to provide educational labor. Richardson notes the futility of putting in the effort required to educate her non-Black undergraduate peers about anti-Black racism when their responses are at best dismissive and at worst abusive:

At times, I get very frustrated: why should it be my responsibility as a black woman to reach out, when historical and contemporary evidence both say that the ones who I reach out to are probably just going to speak over me, ignore me, or blame me for my own problems? This seems neither just nor logical.

I often wonder why I should even bother. I honestly feel that I owe nothing, especially not some manner of education, to my oppressors. Why sacrifice the energy, the mental strength, if it'll be all for naught? It all feels rather self-flagellating sometimes. (2015)

Richardson observes that providing educational labor to one's oppressors is not only pointless but can even be self-destructive when it leaves the laborer worse off and more vulnerable than before. This harm can occur even when the privileged person accepts and acknowledges the marginalized person's explanation. One effect of the privileged sense of entitlement to marginalized persons' time and energy is that the work they do is never enough. Attempts at silencing often follow a marginalized person's efforts to critique or speak out against oppression. This occurs even when the critique of oppression is offered in the spirit of education. For instance, Richardson describes how many of her white undergraduate peers expect her to provide solutions any time she critiques or speaks out against racism or white supremacy:

Because I am so outspoken with my frustrations, many of my white peers look to me as a source of education (which is not necessarily A Bad Thing) and ask me for solutions when I simply mean to vent my anger, and that is also frustrating. I cannot complain unless I also come up with something better. I cannot simply be sad. I really wish that I could just sit in a room, and be sad, and express my emotions constructively with nothing else being demanded of me. (2015)

es the racist sentiment that Black hair worn naturally is unkempt. Perhaps more telling is his wife's response, "You used to be nice but now you're mean." That this white woman perceived Meyerson as unfriendly, aggressive, and "mean" for informing her and her husband that she would not be changing her body in order to prioritize their comfort illustrates the dangers that Black women face when they do not acquiesce to white people's entitled demands, no matter how unreasonable. 
Richardson is not permitted to simply experience pain or express anger about the violence of her oppression. She must produce constructive solutions. The presumption here is that if she cannot produce ways to change to the systems she critiques, then she has no right to critique them or express anger about them. ${ }^{10}$ Richardson too risks being perceived as confirming the Angry Black Woman stereotype when she educates her white peers about racial injustice and oppression. The privileged response to this educational labor is frequently some version of, "Stop complaining and do something about it!" This response paints the speaker as merely angry and erases the labor involved in educating others about oppression. It simultaneously silences the marginalized speaker while demanding even more labor from them.

One way to understand the constraints of the double bind in the context of epistemic exploitation is that harmful stereotypes are ready to be deployed against marginalized persons no matter how they respond to epistemically exploitative demands on their time, labor, and expertise.

\subsection{Default Skeptical Responses}

When marginalized persons offer testimony about their general knowledge or lived experiences of oppression, privileged persons often respond with skepticism about the content of their claims. Skeptical responses are frequently the default even when the privileged demanded the testimony in the first place. These responses may include skepticism that the marginalized person's experience really happened the way they describe or skepticism that their experience falls within a larger pattern of oppression rather than simply being an isolated or anomalous incident. The latter response is often based on the false assumption that malicious or conscious intention is necessary for an act to be oppressive. The privileged may also respond with skepticism about the scope or even existence of interlocking systems of oppression. This skepticism reinforces the oppressive power dynamics that make the skepticism of the privileged possible in the first place. ${ }^{11}$

Skeptical responses to lived experiences of oppression serve to exploit in subtle ways. A person who is privileged by some system of oppression has more

10. The silencing that Richardson experiences is part of the larger pattern of whites expecting Blacks to express their anger and pain eloquently, in ways that whites deem appropriate, even when that anger is about white supremacy's endless attacks on Black lives and constant devaluation of Black humanity.

11. The default skepticism of the privileged is itself an expression of privilege. People who do not face a specific type of oppression have the privilege of remaining ignorant about the ways that oppression exists and manifests. For example, non-disabled persons have the privilege of not knowing whether the buildings they work in are accessible. Cisgender people have the privilege of not knowing the locations of safe, gender-neutral bathrooms. White scholars have the privilege of not knowing that meritocracy has never been a feature of academia, etc. 
limited epistemic access to the nature of that oppression than does a person who is marginalized by it. ${ }^{12}$ Consider a white person who responds with unmitigated skepticism to a person of color's experience of racism. In doing so, she positions herself as the epistemic peer of the person of color with respect to this particular domain. She implicitly suggests that she is as qualified as her conversation partner to evaluate what counts as an experience of racism. This posturing as an epistemic peer effectively functions to tacitly demand a response from the person of color. In a context where the privileged person has framed her opinion and the marginalized person's evaluation as being equally credible, the marginalized person bears a significant risk by failing to respond.

To see this, consider how the norms of debate demand a different response to a substantive objection than they do to a purported objection that is really based on a misunderstanding. A substantive objection to a view requires a substantive response from the view's advocate. If one cannot be produced, the view is consequently weakened by the objection. An objection based on a misunderstanding does not call for a substantive response. Rather than burdening the view's advocate with the task of responding to such an objection, we recognize that it is the job of the confused objector to do the work required in order to correctly understand the view and come to see why their purported objection is misguided. By positioning herself as an epistemic peer and her skepticism as a substantive objection to the marginalized person's claim, the uninformed privileged person who "objects" to the marginalized person's claim about oppression creates the pretense that a substantive response is called for. If the marginalized person fails to respond to the skepticism, effectively giving the privileged objector the last word, the objection appears to be a substantive one that has no response. This serves to legitimize the skepticism in the eyes of the objector as well as bystanders and thus serves to undermine the force of the marginalized person's original claim. This dynamic is produced by the fact that dominantly situated persons frequently take their own misunderstandings to be substantive objections. ${ }^{13}$

The privileged tend to set the terms of debate. A marginalized person who

12. I take this to follow from the fact that a person who experiences some form of oppression has two routes to attaining knowledge about it: 1 ) experiencing it firsthand and 2) learning about it through the testimony of others who experience it. A person who does not experience that oppression has only the latter route available to them.

13. For instance, white philosophers often take their own confused conviction that racism is nothing more than consciously held racial prejudice to be a genuine philosophical view about racism that must be engaged before being rejected. They see themselves as being owed substantive meta-level arguments for why they should rule out a priori any account of racism that allows for the possibility of "reverse racism" and will otherwise refuse to engage in discussions of racism that assume the actual theoretical definition of racism as racial prejudice plus structural power. This is a specific instance of the more general pattern of racial arrogance in which whites claim to disagree with a perspective on racism that challenges their dominant worldview, when in fact they simply do not understand it (DiAngelo 2011). 
fails to respond to a privileged person's conceptually confused skepticism when it is inaccurately framed as a substantive objection risks being seen as losing the debate. ${ }^{14}$ Both participants and spectators are likely to perceive them this way, and this is especially true for online discussions. Being seen as losing the debate leads to further loss of credibility for the marginalized person, who is likely already suffering from a credibility deficit. Default skepticism functions as a mechanism of epistemic exploitation because it creates the tacit demand for a response. This requires the marginalized person to produce further cognitive and emotional labor. Default skepticism is both a response to labor produced under epistemic exploitation and a demand for even more labor. It thus enacts epistemic exploitation through a process of recursion.

A privileged person responding with skepticism to a marginalized person's claims about their generalized knowledge or experience of oppression can produce a number of epistemic harms in addition to epistemic exploitation. A response of default skepticism can have the effect of gaslighting the marginalized person. Gaslighting functions to undermine a person's confidence in their grasp on reality leading to an overall sense of self-doubt and a lack of trust in one's perceptions. ${ }^{15}$ Gaslighting involves raising doubts about a person's ability to accurately perceive and understand events, and can thus harm them in their capacity as a knower (McKinnon in press). Fatima details the cumulative effects of microaggressions against women of color in academia. "When one is constantly given alternate banal explanations for their 'overly-sensitive' perceptions, one loses the epistemic ground they stand on. They cease to give credibility to their own perceptions" (2015). Someone who is gaslighted can actually lose knowledge they once possessed by coming to no longer believe what they previously knew to be the case. When a marginalized person is deprived of knowledge because they lose credence in their understanding of their own experience as a result of gaslighting, this perpetuates epistemic oppression. ${ }^{16}$

Skeptical responses can also lead to testimonial smothering, a self-silencing phenomenon in which a speaker avoids engaging in risky conversations with

14. Though this risk is not limited to cases of epistemic exploitation, it is heightened in these cases. Similar dynamics regarding the perceptions of objections as either substantive or mistaken can arise in any context. However, the distorting effects of identity on differential credibility ascriptions are compounded in debates between privileged and marginalized persons when what is disputed is the nature of oppression.

15. For a philosophical investigation into the wrongs and harms of gaslighting, see Abramson (2014).

16. McKinnon (in press) emphasizes that those who consider themselves to be "allies" frequently commit this type of harm. People who identify as allies claim to stand in solidarity with the oppressed. Because they often receive higher levels of credibility than members of the privileged group who do not claim to be allies and than members of the oppressed group with whom they claim to be allied, they are in a unique position to cause harm through gaslighting. 
a hearer who is perceived to be incompetent because of their demonstrated unwillingness or inability to "gain the appropriate uptake of the proffered testimony" (Dotson 2011: 244). Hearers who repeatedly respond with skepticism to a marginalized speaker's testimony about oppression demonstrate an inability to accept and understand the speaker's testimony in that domain. These conditions create pressure for the marginalized person to engage in testimonial smothering as a means of self-protection. Having to constantly engage in self-silencing creates a hostile environment, and the resulting alienation further entrenches the speaker's marginalization. These phenomena frequently occur alongside epistemic exploitation and exacerbate the marginalization it produces.

\section{Epistemic Exploitation and Epistemic Injustice}

Epistemic exploitation is made possible by the particular social and political structures in which our epistemic practices take place. It is thus subject to interaction effects with other types of epistemic harm. In this section, I explore the ways this phenomenon relates to the epistemic harms that Fricker (2007) identifies as epistemic injustice. Broadly, epistemic injustice is any injustice that harms someone specifically in their capacity as a knower. Fricker identifies two types of epistemic injustice, testimonial injustice and hermeneutical injustice. Both of these can interact with epistemic exploitation to produce compounded epistemic harms and marginalization.

\subsection{Epistemic Exploitation and Testimonial Injustice}

Testimonial injustice occurs when a speaker receives less credibility than they are due as a result of negative identity prejudice. According to Fricker (2007), testimonial injustice is perpetrated against members of groups whose testimony is questioned and disbelieved because of negative prejudicial stereotypes about those groups. Because members of marginalized groups are vulnerable to testimonial injustice, the phenomenon frequently occurs alongside epistemic exploitation and exacerbates the harms it produces. ${ }^{17}$

17. Testimonial injustice can also play a role in producing epistemic exploitation absent deflated credibility ascriptions of marginalized speakers. Davis (2016) argues that testimonial injustice should not be restricted solely to cases involving credibility deficits and that some credibility excesses ascribed to marginalized speakers should be considered testimonial injustices when those speakers are treated as tokens or spokespersons for the marginalized groups to which they belong. Davis emphasizes that tokenization and positive stereotyping can result in the burden to educate falling to the marginalized and that this labor is often extracted under unjust conditions. Thus, testimonial injustice resulting from either a credibility deficit or a credibility surplus can produce or compound epistemic exploitation. 
Consider a situation in which a female graduate student, Summer, denounces the role that sexism played in her department's decision to award all available fellowships to male graduate students. Despite the graduate program's international reputation as a hostile place for women, a male grad student, Dean, demands that Summer explain to him how the fellowship decision is sexist. She responds by noting that the department harbors a high number of male faculty who are serial harassers, that these faculty serve on the fellowship committee, and that the committee generally fails to award merit-based fellowships to women. Summer points out that the chair of the department knows about the harassment but covers it up in order to protect the department's reputation and he continues to let the harassers serve on the fellowship committee. She also relays personal experiences of sexual harassment by male faculty who are committee members. Dean responds by insisting that Summer misinterpreted her experiences of harassment by committee members, and he says that the "real" harassers are just a "few bad apples" incapable of genuinely affecting departmental climate. He asserts that fellowship distribution is meritocratic and that gender bias played no role in the department's decision. He discredits Summer's claims by saying that she is just resentful about not being awarded a fellowship and is therefore blaming sexism for an outcome that was caused by her own shortcomings.

This case demonstrates a number of intertwined epistemic harms. Dean epistemically exploits Summer by demanding that she educate him about an aspect of oppression that she experiences, in this case the department's sexism. When she does provide him with an explanation, he dismisses her claims. His default skeptical response to her experiences of harassment functions to demand further epistemic labor from her. Dean gaslights Summer by telling her that she inaccurately interpreted her experiences of harassment. He also perpetrates testimonial injustice by subjecting her to the negative stereotype of the bitter woman 'crying' sexism and using that to undermine her credibility. This is an instance of a broader pattern in which members of marginalized groups are less likely than privileged persons to be ascribed the credibility they are due. This is particularly true when it comes to claims about the nature of their own oppression.

We can draw an important lesson from this case if we contrast how Dean responds to Summer with how he would respond to the same claims if they were instead made by another male graduate student, Ryan. Dean would be more likely to accept the same explanation of departmental sexism coming from Ryan than he was from Summer. The nature of privilege is that it comes with a credibility surplus. Privileged persons are more likely to believe claims about privilege and oppression when they come from other persons who share 
their privilege. ${ }^{18}$ This has ramifications for how effective at enlightening the privileged epistemic exploitation can be. That testimonial injustice is likely to occur in epistemically exploitative exchanges means that the educational labor performed often fails to result in privileged listeners obtaining knowledge. Thus, even if we were to ignore the additional costs that marginalized persons must bear when educating privileged persons about their oppression, epistemic exploitation would still be a relatively ineffective way of educating the privileged about oppression. The privileged are simply less likely to believe claims about oppression whey they come from those who actually experience it. This is just one of the reasons why privileged persons acting in solidarity with the oppressed must take it upon themselves to educate other members of the privileged group about oppression. ${ }^{19}$

\subsection{Epistemic Exploitation and Hermeneutical Injustice}

Hermeneutical injustice, like testimonial injustice, can contribute to and exacerbate the harms of epistemic exploitation. However, epistemic exploitation usually occurs when the conceptual resources necessary to do the educational work already exist but the dominantly situated choose not to avail themselves of these resources. In these cases, willful hermeneutical ignorance and contributory injustice are compounding factors.

According to Fricker, hermeneutical injustice occurs when there is a dearth of narrative and interpretive resources to describe and understand the experiences of those who are marginalized within society. This occurs because dominant groups have primary control over what hermeneutical resources are produced:

Hermeneutical inequality is inevitably hard to detect. Our interpretive efforts are naturally geared to interests, as we try hardest to understand those things it serves us to understand. Consequently, a group's unequal participate on will tend to show up in a localized manner in hermeneutical hotspots - locations in social life where the powerful have no interest in achieving a proper interpretation, perhaps indeed where they have a positive interest in sustaining the extant misinterpretation ... But then in such a hotspot as this, the unequal hermeneutical participation remains

18. Medina (2013: 57) notes that privileged subjects frequently develop an overinflated sense of entitlement and epistemic arrogance that prevents them both from achieving self-knowledge and from recognizing knowledge in marginally situated knowers.

19. Showing Up for Racial Justice (SURJ) is one activist group that makes this commitment foundational. Their organizing principle is that white people must educate and mobilize other white people in the service of dismantling white supremacy. 
positively disguised by the existing meaning attributed to the behavior and so it is all the more difficult to detect. (Fricker 2007: 153)

On Fricker's picture, hermeneutical injustice occurs when there is a gap in the collective hermeneutical resources that leaves a marginalized group unable to understand or make sense of some aspect of their experience. ${ }^{20}$

When hermeneutical injustice coincides with epistemic exploitation, the combined harms exacerbate epistemic marginalization. If a privileged person demands that a marginalized person explain to them some aspect of their experience of oppression and there are no conceptual resources to draw on, the marginalized person does not even have both of the options that create the double bind. They cannot choose to give in to the epistemically exploitative demand and engage in unpaid labor to enlighten the privileged person, because there are no shared interpretive resources available. At best, they can try to explain their experience using inadequate hermeneutical resources, which will make their claims and their position appear to be unintelligible.

Epistemic exploitation frequently occurs when the hermeneutical resources involved are readily accessible but the privileged person has failed to make use of them. Dotson points out that people who are epistemically oppressed often have no difficulty readily articulating their experiences. "However, those articulations generally fail to gain appropriate uptake according to the biased hermeneutical resources utilized by the perceiver" (2012: 32). It is not that the necessary herme-

20. Fricker illustrates the concept of hermeneutical injustice with a discussion of Susan Brownmiller's account of Carmita Wood's experience of filing for unemployment after leaving a job due to sexual harassment. As there was no box to check on the unemployment application that described her reason for leaving her job, Wood had no other choice than to say that she left for "personal reasons." Fricker identifies the lack of a box to check as an instance of hermeneutical injustice. Interestingly, though Carmita Wood is a Black woman, Fricker never mentions her race. Either Fricker does not know Wood's race, she does not see Wood's race as relevant to her experience, or she avoids mentioning Wood's race because she sees her experience of sexual harassment in the workplace as something that is relevant to 'all' women. While many women face sexual harassment in the workplace, the history of U.S. Black women's experiences of sexual harassment in the workplace is unique. Under slavery, Black women were forced to labor without pay for the profits of white enslavers who systematically used sexual abuse as a tool of control and domination. After emancipation, Black women worked as domestic servants in the homes of white families where they faced sexual harassment and sexual assault by their employers. The limited work available to Black women meant that white domestic employers could continue to subject them to sexual mistreatment with impunity (Collins 2000: 60-63). Today, as Black women remain especially vulnerable to employment discrimination, their lack of job security makes them continued targets for sexual abuse and harassment in the workplace. Ignoring this context as Fricker does whitewashes the particular realities of sexual harassment in the workplace that Black women have experienced because of their marginalized location at the intersection of race-, sex-, and class-based oppression within white supremacist capitalist patriarchy. It also contributes to Black women's hermeneutical marginalization by implicitly denying the relevance of race to their lived experiences of sexual harassment. 
neutical resources have yet to be conceived but that they have not been acknowledged or taken up by dominant groups. In these cases, the issue is not one of hermeneutical injustice but of what Dotson refers to as contributory injustice, the systematic epistemic harm that results from a subject's willfully ignorant use of structurally biased hermeneutical resources in ways that compromise another's epistemic agency. While hermeneutical injustice describes a gap in the epistemic resources available to understand one's experiences, contributory injustice covers cases in which the resources have been introduced but have failed to become part of the persuasively shared epistemic resources because of the epistemic exclusion of their originators. It is a failure of circulation rather than a failure of creation, and it is due to the refusal of dominant groups to acknowledge epistemic resources that resist assimilation into dominant epistemic schemes.

In some cases, the myth that there is a genuine gap in the collective hermeneutical resources is a form of active ignorance that gives the dominantly situated license to engage in epistemic exploitation. Dominantly situated persons may erase or deny the existence of the relevant hermeneutical resources in question. This is one of the functions of default skepticism in epistemically exploitative exchanges. Pohlhaus (2012: 722) identifies willful hermeneutical ignorance as the tendency of the dominantly situated to dismiss epistemic resources such as "date rape" or "heteronormativity" that make sense of experiences and phenomena that are primarily discernible to the marginally situated. She writes,

Good epistemic resources ... make sense of the experienced world, and if one's situatedness does not make salient those aspects of the world for which particular resources are useful, the dominantly situated knower can use that fact to dismiss those resources before learning to use them. (2012: 722)

Erasing and dismissing these resources allows the dominantly situated to invoke the pretense that no such hermeneutical resources exist, which in turn supports their position that they cannot and should not be held accountable for their ignorance. This pretense is also used to imply that the marginalized person has an obligation to educate them by producing these 'missing' resources. After all, as the willfully ignorant argument goes, if the resources aren't out there and the marginalized person won't teach them, how can the dominantly situated person be expected to learn?

\section{Epistemic Exploitation as Epistemic Oppression}

Situating epistemic exploitation within Dotson's (2012; 2014) framework of epistemic oppression helps to shed light on its broader social and political func- 
tions. Dotson defines epistemic oppression as "a persistent and unwarranted infringement on the ability to utilize persuasively shared epistemic resources that hinders one's contributions to knowledge production" (2014: 2). Epistemic oppression is characterized by sustained, unjustified compromise to the epistemic agency of some population, frequently one that has experienced historical, social, and political marginalization. ${ }^{21}$ Epistemic agency is understood as the ability to use "shared epistemic resources within a given epistemic community in order to participate in knowledge production and, if required, the revision of those same resources" (2012: 24).

While privileged demands for education and enlightenment from marginalized people may appear to be invitations to participate in knowledge production, the ideas and claims marginalized people put forward are readily dismissed and are not taken to be genuine contributions to knowledge. This is evidenced by how frequently marginalized persons have to make the same claims over and over again and are met with the same dismissive responses every time-a pattern noted by Cooper (2015) and Richardson (2015). The privileged demonstrate entitlement to the labor and means of production of knowledge but fail to actually recognize the goods produced as contributions to knowledge.

How can we make sense of the fact that the privileged demand labor from the marginalized and then fail to make use of the fruits of that labor? The answer lies in the role that epistemic exploitation plays in upholding the active ignorance of the dominantly situated. Consider Mills's (2007) notion of white ignorance, an actively upheld form of ignorance masquerading as knowledge that is mandated by white supremacy. The structure and ideology of white supremacy encourage its beneficiaries to meet a set of standards of cognition that effectively create a tacit agreement to misinterpret the world. According to Mills, white supremacy prescribes and demands "white misunderstanding, misrepresentation, evasion, and self-deception on matters related to race" (1997: 18). Whites must maintain a coherent narrative of racism being located solely in the past in the face of omnipresent evidence to the contrary. This requires sophisticated efforts to not only suppress accurate information but to distribute false information. It also requires the ability to reinterpret pervasive evidence of structural inequality as compatible with post-racialism and even as providing support for colorblind racial ideology (Baran 2013; Neville 2009). ${ }^{22}$

21. Dotson emphasizes that while epistemic oppression is often the result of social and political oppression, there is still a distinctly and irreducibly epistemic dimension of oppression.

22. Neville, Poteat, Lewis, and Spanierman (2014) characterize colorblind racial ideology (CBRI) as "a set of beliefs that deny, minimize, and distort the existence of racism in its many forms (e.g., individual, interpersonal, cultural, and institutional) and the role of race in people's lives" (2014: 180). They also describe CBRI as a "system-justifying ideology or a worldview that helps to 
When ignorance is more than a mere absence of knowledge, maintaining ignorance in the face of resources that threaten to expose it requires work. Specifically, it requires the construction of a narrative on which dismissing these resources without considering them appears reasonable. As noted earlier, Pohlhaus identifies the common pattern in which dominantly situated knowers have access to epistemic resources created from the experiences of marginalized knowers but they pre-emptively dismiss these resources out of hand: "Marginally situated knowers actively resist epistemic domination through interaction with other resistant knowers, while dominantly situated knowers nonetheless continue to misunderstand and misinterpret the world" (2012: 716). When the privileged demand and then reject the conceptual and epistemic goods that the marginalized produce, they erase practices of epistemic resistance. This functions to confirm the myth that there are no valuable or useful epistemic resources besides those that fit into dominant theoretical frameworks. The marginalized can then be made to appear responsible for their own epistemic oppression. Epistemic exploitation upholds dominant conceptual schemas by maintaining the illusion that there simply are no viable alternatives.

The epistemic products of the labor of the marginalized play an important dialectical role in the disinformation produced by dominantly situated knowers. The dominantly situated treat them as fodder for skeptical responses and harvest them for content that can be developed into straw arguments and rejected out of hand. This practice gives the appearance of a balanced, reasoned debate from which the privileged position of active ignorance emerges as the rational victor. The dominantly situated feign engagement with the marginalized but refuse to listen to them. They do not invite them to update, reframe, or contribute to the discourses they control. The privileged demand and dismiss the epistemic efforts of the marginalized in a cycle of epistemic exploitation and contributory injustice. This recurring pattern exemplifies the persistent epistemic exclusion that is the hallmark of epistemic oppression. Despite their exclusion from dominant discourses, marginalized knowers continue practices of epistemic resistance, enacting Lorde's project of altering the present and constructing the future.

\section{Concluding Remarks}

Epistemic exploitation is a form of epistemic oppression characterized by unrecognized, uncompensated, emotionally taxing epistemic labor. Because of the

rationalize racial inequalities (2014: 180). Empirical research supports a connection between high CBRI and greater modern racism (Awad, Cokley, \& Ravitch 2005). 
double bind that marginalized persons face, the epistemically exploitative conditions under which the dominantly situated extract their labor are coercive. Default skeptical responses from the privileged discredit and erase the epistemic resources of the marginalized and create demand for even more unrecognized labor. Epistemic exploitation reproduces and upholds the active ignorance that is integral to maintaining dominant epistemic frameworks. Conceptualizing epistemic exploitation as a form of epistemic oppression positions us to address its structural causes, recognize the ways it harms epistemic communities, and ultimately envision the structural remedies that it demands.

\section{Acknowledgements}

Thanks to the following people for their invaluable comments, contributions, and insights: Derek Anderson, Nathaniel Adam Tobias Coleman, Kristie Dotson, Saba Fatima, Hannah Giorgis, Patrick Grzanka, Rachel McKinnon, Lionel K. McPherson, Deborah Mühlebach, A.y. Odedeyi, Andrea Richardson, and Eboni Winford.

\section{References}

Abramson, Kate (2014). Turning Up the Lights on Gaslighting. Philosophical Perspectives, 28(1), 1-30. https:/doi.org/10.1111/phpe.12046

Ahmed, Sara (2012). On Being Included: Racism and Diversity in Institutional Life. Duke University Press. https:/doi.org/10.1215/9780822395324

Ajayi, Luvvie (2015, February 23). About Patricia Arquette's Backstage Speech at the 2015 Oscars [Web log post]. Awesomely Luvvie. Retrieved from http://www.awesomelyluvvie.com/2015/02/about-patricia-arquette-backstage-2015-oscars.html

Awad, G. H., K. Cokley, and J. Ravitch (2005). Attitudes Toward Affirmative Action: A Comparison of Color-Blind versus Modern Racist Attitudes. Journal of Applied Social Psychology, 35(7), 1384-1399. https:/doi.org/10.1111/j.1559-1816.2005.tb02175.x

Bailey, Moya (2010, March 14). They Aren't Talking about Me ... Crunk Feminist Collective. Retrieved from http://www.crunkfeministcollective.com/2010/03/14/they-arenttalking-about-me/

Bailey, Moya (2014, April 27). More on the Origin of Misogynoir [Web log post]. Retrieved from http://moyazb.tumblr.com/post/84048113369/more-on-the-origin-ofmisogynoir

Baran, Stephanie (2013). Parsing White Supremacy: An Exploratory Study of Political Thoughts and Beliefs (master's thesis). Heathwood Institute and Press.

Canton, Cecil (2013, December 5). "The 'Cultural Taxation' of Faculty of Color in the Academy." California Faculty Magazine. Retrieved from http://www.calfac.org/magazine-article/cultural-taxation-faculty-color-academy

Clark, R., N. B. Anderson, V. R. Clark, and D. R. Williams (1999). Racism as a Stressor for African Americans: A Biopsychosocial Model. American Psychologist, 54(10), 805816. https:/doi.org/10.1037/0003-066X.54.10.805 
Collins, Patricia Hill. (200o). Black Feminist Thought: Knowledge, Consciousness, and the Politics of Empowerment. Routledge.

Cooper, Brittney (2015, February 25). Black America's Hidden Tax: Why This Feminist of Color is Going on Strike. Salon. Retrieved from http://www.salon.com/2015/02/25/ black_americas_hidden_tax_why_this_feminist_of_color_is_going_on_strike/

Cox, Aimee (2008). Women of Color Faculty at the University of Michigan: Recruitment, Retention, and Campus Climate. Report for the Center for the Education of Women, University of Michigan. Retrieved from http://cew.umich.edu/sites/default/files/AimeeCoxWOCFull2_1.pdf

Davis, Emmalon (2016). Typecasts, Tokens, and Spokespersons: A Case for Credibility Excess as Testimonial Injustice. Hypatia, 31(2), 1-17.https:/doi.org/10.1111/hypa.12251

DiAngelo, Robin (2011). White Fragility. International Journal of Critical Pedagogy, 3(3), $54-70$.

Dotson, Kristie (2011). Tracking Epistemic Violence, Tracking Practices of Silencing. Hypatia, 26(2), 236-257. https:/doi.org/10.1111/j.1527-2001.2011.01177.x

Dotson, Kristie (2012). A Cautionary Tale: On Limiting Epistemic Oppression. Frontiers, 33(1), 24-47. https:/doi.org/10.5250/fronjwomestud.33.1.0024

Dotson, Kristie (2014). Conceptualizing Epistemic Oppression. Social Epistemology, 28(2), 115-138. https:/doi.org/10.1080/02691728.2013.782585

Fatima, Saba (2015, April 20). Am I being Paranoid? Being a Woman of Color in Academia [Web log post]. Southern Illinois University-Edwardsville Women's Studies Program Wordpress. Retrieved from https://siuewmst.wordpress.com/2015/04/20/am-ibeing-paranoid-being-a-woman-of-color-in-academia/

Fricker, Miranda (2007). Epistemic Injustice: Power and the Ethics of Knowing. Oxford University Press. https:/doi.org/10.1093/acprof:oso/9780198237907.001.0001

Giorgis, Hannah (2012). How to be an Ally. Dartmouth Center for Women \& Gender. Originally retrieved from http://dartmouthcwg.com/2012/05/01/how-to-be-an-ally/ (Currently available from http://keepitchecked.tumblr.com/post/29462861811/how-tobe-an-ally)

Giorgis, Hannah (2014, Jun 16). Monday Morning Meditation [Web log post]. Tumblr. Retrieved from http://ethiopienne.com/post/88957880553/monday-morning-meditation-do-not-waste-time

Jacobsen, Margaret (2015, December 17). I Recorded The Racist Things People Said \& Did To Me For 2 Weeks. Romper. Retrieved from https://www.romper.com/p/i-recorded-the-racist-things-people-said-did-to-me-for-2-weeks-1690

K॰ra (2014, December 10). How to Uphold White Supremacy by Focusing on Diversity and Inclusion [Web log post]. Model View Culture. Retrieved from https://modelviewculture.com/pieces/how-to-uphold-white-supremacy-by-focusing-on-diversityand-inclusion

Landrine, Hope, Elizabeth Klonoff, Jeannine Gibbs, Vickie Manning, and Marlene Lund. (1995). Physical and Psychiatric Correlates of Gender Discrimination: An Application of the Schedule of Sexist Events. Psychology of Women Quarterly, 19(4), 473-492. https:/doi.org/10.1111/j.1471-6402.1995.tb00087.x

Lorde, Audre ( 2007). The Master's Tools Will Never Dismantle The Master's House. In Sister Outsider: Essays and Speeches (110-114). Crossing Press.

Lorde, Audre (1995). Age, Race, Class, and Sex: Women Redefining Difference. In Beverly Guy-Sheftal (Ed.), Words of Fire: An Anthology of African American Feminist Thought (284-291). The New Press.

Ergo • vol. 3, no. 22 • 2016 
Maharawal, Manissa McCleave (2011, October 11). So Real it Hurts. The Occupied Wall Street Journal. Retrieved from http://www.leftturn.org/so-real-it-hurts-notes-occupywall-street

McKenzie, Mia (2014). No More Allies. In Black Girl Dangerous: On Race, Queerness, Class, and Gender. BGD Press.

McKinnon, Rachel (in press). Allies Behaving Badly: Gaslighting as Epistemic Injustice. In Gaile Pohlhaus Jr., Ian James Kidd, and José Medina (Eds.), Routledge Handbook on Epistemic Injustice. Routledge.

Medina, José (2013). The Epistemology of Resistance. Oxford University Press. https:/doi. org/10.1093/acprof:oso/9780199929023.001.0001

Meyerson, Collier (2015, Jan 20). When the Opera Acts Like It's Never Seen a Black Person Before. Jezebel. Retrieved from http://jezebel.com/when-the-opera-acts-like-itsnever-seen-a-black-person-1680149691

Mills, Charles (2007). White Ignorance. In Shannon Sullivan and Nancy Tuana (Eds.). Race and Epistemologies of Ignorance (11-38). State University of New York Press.

Mills, Charles (1997). The Racial Contract. Cornell University Press.

Morrison, Toni (1975, May 30). A Humanistic View. In Public Dialogue on the American Dream Theme, Part 2. Panel conducted by the Portland State Black Studies Center.

Neville, Helen (2009). Rationalizing the Racial Order: Racial Color-Blindness as a Legitimizing Ideology. In Theodore Koditschek, Sundiata Keita Cha-Jua, and Helen Neville (Eds.), Race Struggles (115-133). University of Illinois Press.

Neville, Helen, Paul Poteat, Jioni Lewis, and Lisa Spanierman (2014). Changes in White College Students' Color-Blind Racial Ideology over 4 Years: Do Diversity Experiences Make a Difference? Journal of Counseling Psychology, 61(20), 179-190. https:/doi. org/10.1037/a0035168

Niemann, Yolanda Flores (1999). The Making of a Token: A Case Study of Stereotype Threat, Stigma, Tokenism, and Racism in Academe. Frontiers: A Journal of Women Studies, 20(1), 111-134. https:/doi.org/10.2307/3346994

Pieterse, Alex, Nathan Todd, Helen Neville, and Robert Carter (2012). Perceived Racism and Mental Health among Black American Adults: A Meta-Analytic Review." Journal of Counseling Psychology, 59(1), 1-9. https:/doi.org/10.1037/a0026208

Pohlhaus, Gaile (2012). Relational Knowing and Epistemic Injustice: Toward a Theory of Willful Hermeneutical Ignorance. Hypatia 27(4), 715-735.

Richardson, Andrea (2015, February 8) The Master's Tools [Web log post]. Black Feminist Thought in Big Orange Country. Retrieved from https://philosofyre.wordpress. com/2015/02/08/the-masters-tools/

Schwartz, Julianna Britto (2014, May 30) An Open Letter to Privileged People Who Play Devil's Advocate. Feministing. Retrieved from http://feministing.com/2014/05/30/anopen-letter-to-privileged-people-who-play-devils-advocate/

Trudy (2014, April 28). Explanation of Misogynoir [Web log post]. Gradient Lair. Retrieved from http://www.gradientlair.com/post/84107309247/define-misogynoiranti-black-misogyny-moya-bailey-coined

Wilson, Kirby (2015, February 11). Lack of Diversity Leads to Burden on Professors of Color. The Duke Chronicle. Retrieved from http://www.dukechronicle.com/article/2015/02/lack-diversity-leads-burden-professors-color 